Original Article

\title{
Hubungan Sumber Informasi dengan Pengetahuan Tentang Kesehatan Reproduksi Remaja Di Provinsi Sulawesi Utara
}

\section{Relationship of Information Sources with Knowledge of Adolescent Reproductive Health in North Sulawesi Province}

\author{
Ardiansa A.T. Tucunan*1, Brigitte Inez Maitimo², Irma Febrie Tulungen² \\ ${ }^{1}$ Fakultas Kesehatan Masyarakat Universitas Sam Ratulangi, Manado, Indonesia \\ ${ }^{2}$ BKKBN Provinsi Sulawesi Utara, Indonesia \\ (*ardiansa_tucunan@unsrat.ac.id)
}

\begin{abstract}
ABSTRAK
Tujuan penelitian ini untuk mengetahui hubungan sumber informasi terhadap pengetahuan remaja tentang kesehatan reproduksi. Jenis penelitian ini adalah kuantitatif bersifat deskriptif analitik, dengan menggunakan raw data sekunder dari SKAP 2019, dengan sampel melibatkan remaja di Sulawesi Utara berusia 10-24 tahun berjumlah 496 remaja. Instrumen berupa kuesioner SKAP 2019. Analisis statistik menggunakan uji chi-square. Hubungan sumber informasi media dengan pengetahuan remaja tentang KRR yang berhubungan signifikan secara statistik hanya pengetahuan tentang masa subur $(0,012)$ dan umur terendah aman melahirkan $(0,001)$. Variabel sumber informasi dari petugas kesehatan/masyarakat yang berhubungan dengan pengetahuan KRR remaja yaitu pengetahuan hamil sekali melakukan hubungan $(0,041)$, rencana menikah $(0,011)$, umur terendah aman melahirkan $(0,000)$. Variabel pengetahuan KRR remaja yang berhubungan signifikan dengan sumber informasi institusi yaitu umur terendah aman melahirkan $(0,015)$, akibat menikah muda bagi kesehatan anak $(0,022)$. Kesimpulan yaitu sebagian besar remaja di Sulawesi Utara tidak mendapatkan informasi yang memadai dari berbagai pihak seperti petugas kesehatan/masyarakat, institusi dan juga dari media.
\end{abstract}

Kata kunci : Sumber Informasi Media, Pengetahuan, Kesehatan Reproduksi Remaja

\section{ABSTRACT}

The purpose of this study was to determine the relationship of information sources to adolescent knowledge about reproductive health. This type of research is quantitative descriptive-analytic, using secondary raw data from SKAP 2019, with a sample involving adolescents in North Sulawesi aged 1024 years totaling 496 adolescents. The instrument is the 2019 SKAP questionnaire. Statistical analysis uses the chi-square test. The relationship between media information sources and adolescent knowledge about RRR was statistically significant, only knowledge about the fertile period (0.012) and the lowest age at which it was safe to give birth (0.001). Variable sources of information from health workers/community related to adolescent KRR knowledge are knowledge of pregnant once having intercourse (0.041), planning to marry (0.011), the lowest age safe giving birth (0.000). Adolescent KRR knowledge variable that is significantly related to institutional information sources is the lowest age for safe childbirth (0.015), the effect of early marriage on children's health (0.022). The conclusion is that most teenagers in North Sulawesi do not get adequate information from various parties such as health/community officers, institutions and also from the media.

Keywords : Media Information Resources, Knowledge, Adolescent Reproductive Health

https://doi.org/10.33860/jik.v15i4.474

(C) 2021 by the authors. Submitted for possible open access publication under the terms and conditions of the Creative

Commons Attribution (CC BY SA) license (https://creativecommons.org/licenses/by-sa/4.0/). 


\section{PENDAHULUAN}

Masalah kesehatan reproduksi adalah salah satu isu penting yang perlu diketahui remaja ${ }^{1}$. Hal ini perlu diketahui agar remaja dapat melewati masa remajanya dengan aman. Ini menjadi sesuatu yang krusial, karena jika remaja memiliki kesehatan rreproduksi yang buruk, akan berdampak pada rendahnya kualitas Indeks Sumberdaya manusia, dan tentu saja akan menghambat pembangunan nasional. Dari sekian banyak faktor yang mempengaruhi perilaku di kalangan remaja, salah satu faktor pendorong remaja berperilaku berisiko terhadap kesehatan reproduksi adalah informasi yang kurang memadai tentang kesehatan reproduksi yang dimiliki remaja ${ }^{2}$.

Banyak remaja yang tidak memiliki informasi yang cukup mengenai kesehatan dan juga memiliki persepsi yang keliru tentang kesehatan reproduksi ${ }^{3}$. Akibat kurangnya pemahaman yang memadai tersebut, banyak remaja yang tidak sadar telah melaku aktivitas berisiko terhadap kesehatan reproduksinya ${ }^{4}$.

Provinsi Sulawesi Utara mempunyai masyarakat yang memiliki budaya yang cukup 'open minded' di mana masyarakatnya bisa terbuka dengan semua budaya yang ada. Keterbukaan ini bisa bernuansa positif, sekaligus juga negatif. Para remaja, yang seharusnya menjadi generasi penerus bangsa kelak, sudah sangat akrab dengan seks bebas dan pernikahan dini, akibatnya banyak yang sudah tidak bisa melanjutkan studi di bangku pendidikan karena harus menikah dini dan merawat anaknya ${ }^{5}$. Salah satu faktor yang sangat mempengaruhi pengetahuan tentang kesehatan reproduksi remaja di Sulawesi utara yaitu minimnya sumber informasi tentang kesehatan reproduksi bagi remaja tersebut, yang diperoleh dari media, petugas maupun masyarakat dan juga institusi-isntitusi yang bertanggungjawab untuk memperkenalkan tentang kesehatan reproduksi remaja; sehingga para remaja ini mencari identitasnya sendiri dan keluar dari arah yang benar mengenai kesehatan reproduksinya ${ }^{6}$.

Sumber informasi kesehatan reproduksi remaja diperoleh dari berbagai sumber yang cukup banyak ${ }^{7}$, baik dalam keluarga, masyarakat maupun lembaga-lembaga formal/informal yang memberikan informasi yang benar, sehingga dari informasi yang benar inilah, pengetahuan remaja tentang kesehatan reproduksinya dapat meningkat dengan baik sehingga tidak mengarah kepada perilaku seksual yang tidak bertanggungjawab.

Tujuan penelitian ini untuk mengetahui hubungan sumber informasi terhadap pengetahuan remaja tentang kesehatan reproduksi.

\section{METODE PENELITIAN}

Penelitian ini bersifat deskriptif analitik dengan menggunakan data sekunder yaitu Survei Kinerja Dan Akuntabilitas Program (SKAP) pada tahun 2019 dengan jumlah remaja yaitu 496 orang yang berusia 10-24 tahun. Uji statistik yang digunakan yaitu chi-square dengan menganalisis hubungan antar variabel sumber informasi baik dari media, petugas/masyarakat maupun institusi dengan pengetahuan remaja tentang kesehatan reproduksi.

\section{HASIL}

Tabel 1 menunjukkan bahwa sumber informasi yang berasal dari media ada hubungan signifikan dengan pengetahuan tentang masa subur seorang wanita $(0,012)$; tidak ada hubungan antara variabel sumber informasi dari media dengan pengetahuan tentang hamil sekali melakukan hubungan seks $(0,07)$; tidak ada hubungan antara sumber informasi media dengan pengetahuan tentang umur perempuan sebaiknya menikah pertama kali $(0,724)$; tidak ada hubungan antara sumber informasi dengan pengetahuan tentang umur sebaiknya laki-laki menikah pertama kali $(0,788)$; tidak ada hubungan antara sumber informasi media dengan pengetahuan tentang rencana menikah $(0,499)$; tidak ada hubungan antara sumber informasi media dengan pengetahuan umur perempuan sebaiknya punya anak pertama $(0,566)$; ada hubungan yang signifikan antara sumber informasi media dengan pengetahuan umur terendah wanita aman melahirkan $(0,001)$; tidak ada hubungan antara sumber informasi media dengan pengetahuan umur tertinggi wanita aman melahirkan $(0,799)$; tidak ada hubungan antara sumber informasi media dengan pengetahuan akibat menikah usia muda bagi kesehatan ibu $(0,319)$; tidak ada hubungan antara sumber informasi media dengan pengetahuan akibat menikah muda bagi kesehatan anak $(0,190)$; tidak ada hubungan antara sumber informasi media dengan pengetahuan akibat menikah 
muda bagi psikologi $(1,000)$; tidak ada hubungan antara sumber informasi media dengan pengetahuan akibat menikah muda pada sosial ekonomi $(0,377)$.

Tabel 1 Sumber informasi dari media dan pengetahuan KRR

\begin{tabular}{|c|c|c|c|c|c|}
\hline \multirow{3}{*}{$\begin{array}{l}\text { Sumber informasi berasal dari } \\
\text { media }\end{array}$} & \multicolumn{4}{|c|}{ Pengetahuan Kesehatan Reproduksi Remaja } & \multirow{3}{*}{ Nilai $F_{1}$} \\
\hline & \multicolumn{2}{|c|}{ Tinggi } & \multicolumn{2}{|c|}{ Rendah } & \\
\hline & $\mathbf{n}$ & $\%$ & $\mathbf{n}$ & $\%$ & \\
\hline \multicolumn{6}{|l|}{ Masa subur } \\
\hline Memadai & 6 & 1,2 & 19 & 3,8 & \multirow[t]{2}{*}{0,012} \\
\hline Tidak memadai & 35 & 7,1 & 436 & 87,9 & \\
\hline \multicolumn{6}{|l|}{ Hamil sekali hubungan } \\
\hline Memadai & 22 & 4,4 & 3 & 0,6 & \multirow[t]{2}{*}{0,07} \\
\hline Tidak memadai & 327 & 65,9 & 144 & 29,0 & \\
\hline \multicolumn{6}{|c|}{ Umur perempuan sebaiknya menikah pertama } \\
\hline Memadai & 3 & 0,6 & 22 & 4,4 & \multirow[t]{2}{*}{0,724} \\
\hline Tidak memadai & 45 & 9,1 & 426 & 85,9 & \\
\hline \multicolumn{6}{|c|}{ Umur laki-laki sebaiknya menikah pertama } \\
\hline Memadai & 7 & 1,2 & 18 & 3,6 & \multirow{2}{*}{0,788} \\
\hline Tidak memadai & 154 & 31,0 & 317 & 63,9 & \\
\hline \multicolumn{6}{|l|}{ Rencana menikah } \\
\hline Memadai & 15 & 3,0 & 10 & 2,0 & \multirow[t]{2}{*}{0,499} \\
\hline Tidak memadai & 240 & 48,4 & 231 & 46,6 & \\
\hline \multicolumn{6}{|c|}{ Umur perempuan sebaiknya punya anak pertama } \\
\hline Memadai & 23 & 4,6 & 2 & 0,4 & \multirow[t]{2}{*}{0,556} \\
\hline Tidak memadai & 405 & 81,7 & 66 & 13,3 & \\
\hline \multicolumn{6}{|l|}{ Umur terendah aman melahirkan } \\
\hline Memadai & 7 & 1,4 & 18 & 3,6 & \multirow[t]{2}{*}{0,001} \\
\hline Tidak memadai & 25 & 5,0 & 446 & 89,9 & \\
\hline \multicolumn{6}{|l|}{ Umur tertinggi aman melahirkan } \\
\hline Memadai & 4 & 0,8 & 21 & 4,2 & \multirow[t]{2}{*}{0,799} \\
\hline Tidak memadai & 95 & 19,2 & 376 & 75,8 & \\
\hline \multicolumn{6}{|c|}{ Akibat menikah muda bagi kesehatan ibu } \\
\hline Memadai & 4 & 0,8 & 21 & 4,2 & \multirow[t]{2}{*}{0,319} \\
\hline Tidak memadai & 48 & 9,7 & 423 & 85,3 & \\
\hline \multicolumn{5}{|c|}{ Akibat menikah muda bagi kesehatan anak } & \\
\hline Memadai & 2 & 0,4 & 23 & 4,6 & \multirow[t]{2}{*}{0,190} \\
\hline Tidak memadai & 14 & 2,8 & 457 & 92,1 & \\
\hline \multicolumn{6}{|c|}{ Akibat menikah muda bagi psikologi } \\
\hline Memadai & 9 & 1,8 & 16 & 3,2 & \multirow[t]{2}{*}{1,000} \\
\hline Tidak memadai & 172 & 34,7 & 299 & 60,3 & \\
\hline Akibat menikah muda pada sos & ekonon & & & & \\
\hline Memadai & 5 & 1,0 & 20 & 4,0 & 0,377 \\
\hline Tidak memadai & 65 & 13,1 & 406 & 81,9 & \\
\hline
\end{tabular}

Tabel 2 Sumber informasi petugas/masyarakat dan pengetahuan dan perilaku KRR

\begin{tabular}{|c|c|c|c|c|c|}
\hline \multirow{3}{*}{$\begin{array}{c}\text { Sumber informasi } \\
\text { berasal dari petugas/ } \\
\text { masyarakat }\end{array}$} & \multicolumn{4}{|c|}{$\begin{array}{c}\text { Pengetahuan dan Perilaku Kesehatan Reproduksi } \\
\text { Remaia }\end{array}$} & \multirow{3}{*}{ Nilai p } \\
\hline & \multicolumn{2}{|c|}{ Tinggi } & \multicolumn{2}{|c|}{ Rendah } & \\
\hline & $\mathbf{n}$ & $\%$ & $\mathbf{n}$ & $\%$ & \\
\hline \multicolumn{6}{|l|}{ Masa subur } \\
\hline Memadai & 8 & 1,6 & 58 & 11,7 & 0,326 \\
\hline Tidak memadai & 33 & 6,7 & 397 & 80,0 & \\
\hline \multicolumn{6}{|l|}{ Hamil sekali hubungan } \\
\hline Memadai & 54 & 10,9 & 12 & 2,4 & 0,041 \\
\hline Tidak memadai & 295 & 59,5 & 135 & 27,2 & \\
\hline \multicolumn{6}{|c|}{ Umur perempuan sebaiknya menikah pertama } \\
\hline Memadai & 7 & 1,4 & 59 & 11,9 & 0,960 \\
\hline
\end{tabular}




\begin{tabular}{|c|c|c|c|c|c|}
\hline Tidak memadai & 41 & 8,3 & 389 & 78,4 & \\
\hline \multicolumn{6}{|c|}{ Umur laki-laki sebaiknya menikah pertama } \\
\hline Memadai & 26 & 5,2 & 40 & 8,1 & \multirow{2}{*}{0,250} \\
\hline Tidak memadai & 135 & 27,2 & 295 & 59,5 & \\
\hline \multicolumn{6}{|c|}{ Rencana menikah } \\
\hline Memadai & 44 & 8,9 & 22 & 4,4 & \multirow[t]{2}{*}{0,011} \\
\hline Tidak memadai & 211 & 42,5 & 219 & 44,2 & \\
\hline \multicolumn{6}{|c|}{ Umur perempuan sebaiknya punya anak pertama } \\
\hline Memadai & 59 & 11,9 & 7 & 1,4 & \multirow[t]{2}{*}{0,552} \\
\hline Tidak memadai & 369 & 74,4 & 61 & 12,3 & \\
\hline \multicolumn{6}{|c|}{ Umur terendah aman melahirkan } \\
\hline Memadai & 13 & 2,6 & 53 & 10,7 & \multirow[t]{2}{*}{0,000} \\
\hline Tidak memadai & 19 & 3,8 & 411 & 82,9 & \\
\hline \multicolumn{6}{|c|}{ Umur tertinggi aman melahirkan } \\
\hline Memadai & 13 & 2,6 & 53 & 10,7 & \multirow[t]{2}{*}{1,000} \\
\hline Tidak memadai & 86 & 17,3 & 344 & 69,4 & \\
\hline \multicolumn{6}{|c|}{ Akibat menikah muda bagi kesehatan ibu } \\
\hline Memadai & 9 & 1,8 & 57 & 11,5 & \multirow[t]{2}{*}{0,495} \\
\hline Tidak memadai & 43 & 8,7 & 387 & 78,0 & \\
\hline \multicolumn{6}{|c|}{ Akibat menikah muda bagi kesehatan anak } \\
\hline Memadai & 4 & 0,8 & 62 & 12,5 & \multirow[t]{2}{*}{0,249} \\
\hline Tidak memadai & 12 & 2,4 & 418 & 84,3 & \\
\hline \multicolumn{6}{|c|}{ Akibat menikah muda bagi psikologi } \\
\hline Memadai & 25 & 5,0 & 41 & 8,3 & \multirow[t]{2}{*}{0,909} \\
\hline Tidak memadai & 156 & 31,5 & 274 & 55,2 & \\
\hline \multicolumn{6}{|c|}{ Akibat menikah muda pada sosial ekonomi } \\
\hline Memadai & 8 & 1,6 & 58 & 11,7 & \multirow[t]{2}{*}{0,757} \\
\hline Tidak memadai & 62 & 12,5 & 368 & 74,2 & \\
\hline
\end{tabular}

Tabel 2 menunjukkan bahwa sumber informasi yang berasal dari petugas/masyarakat tidak ada hubungan signifikan dengan pengetahuan tentang masa subur seorang wanita $(0,326)$; ada hubungan antara variabel sumber informasi dari petugas/masyarakat dengan pengetahuan tentang hamil sekali melakukan hubungan seks $(0,041)$; tidak ada hubungan antara sumber informasi dari petugas/masyarakat dengan pengetahuan tentang umur perempuan sebaiknya menikah pertama kali $(0,960)$; tidak ada hubungan antara sumber informasi dari petugas/masyarakat dengan pengetahuan tentang umur sebaiknya laki-laki menikah pertama kali $(0,250)$; ada hubungan antara sumber informasi dari petugas/masyarakat dengan pengetahuan tentang rencana menikah $(0,011)$; tidak ada hubungan antara sumber informasi dari petugas/masyarakat dengan pengetahuan umur perempuan sebaiknya punya anak pertama $(0,552)$; ada hubungan yang signifikan antara sumber informasi dari petugas/masyarakat dengan pengetahuan umur terendah wanita aman melahirkan $(0,000)$; tidak ada hubungan antara sumber informasi dari petugas/masyarakat dengan pengetahuan umur tertinggi wanita aman melahirkan $(1,000)$; tidak ada hubungan antara sumber informasi dari petugas/masyarakat dengan pengetahuan akibat menikah usia muda bagi kesehatan ibu $(0,495)$; tidak ada hubungan antara sumber informasi dari petugas/masyarakat dengan pengetahuan akibat menikah muda bagi kesehatan anak $(0,249)$; tidak ada hubungan antara sumber informasi dari petugas/masyarakat dengan pengetahuan akibat menikah muda bagi psikologi $(0,909)$; tidak ada hubungan antara sumber informasi dari petugas/masyarakat dengan pengetahuan akibat menikah muda pada sosial ekonomi $(0,757)$.

Tabel 3 menunjukkan: sumber informasi yang berasal dari institusi tidak ada hubungan signifikan dengan pengetahuan tentang masa subur seorang wanita $(0,430)$; tidak ada hubungan antara variabel sumber informasi dari institusi dengan pengetahuan tentang hamil sekali melakukan hubungan seks $(0,082)$; tidak ada hubungan antara sumber informasi dari institusi dengan pengetahuan tentang umur perempuan sebaiknya menikah pertama kali $(0,723)$; tidak ada hubungan antara sumber informasi dari institusi dengan pengetahuan tentang umur sebaiknya laki-laki menikah pertama kali $(0,122)$; tidak ada hubungan antara sumber informasi dari institusi 
dengan pengetahuan tentang rencana menikah $(0,430)$; tidak ada hubungan antara sumber informasi dari institusi dengan pengetahuan umur perempuan sebaiknya punya anak pertama $(1,000)$; ada hubungan yang signifikan antara sumber informasi dari institusi dengan pengetahuan umur terendah wanita aman melahirkan $(0,015)$; tidak ada hubungan antara sumber informasi dari institusi dengan pengetahuan umur tertinggi wanita aman melahirkan $(1,000)$; tidak ada hubungan antara sumber informasi dari institusi dengan pengetahuan akibat menikah usia muda bagi kesehatan ibu $(0,182)$; ada hubungan antara sumber informasi dari institusi dengan pengetahuan akibat menikah muda bagi kesehatan anak $(0,022)$; tidak ada hubungan antara sumber informasi dari institusi dengan pengetahuan akibat menikah muda bagi psikologi $(0,812)$; tidak ada hubungan antara sumber informasi dari institusi dengan pengetahuan akibat menikah muda pada sosial ekonomi $(0,643)$.

Tabel 3. Sumber informasi institusi dan pengetahuan dan perilaku KRR

\begin{tabular}{|c|c|c|c|c|c|}
\hline \multirow{3}{*}{$\begin{array}{c}\text { Sumber informasi berasal } \\
\text { dari institusi }\end{array}$} & \multicolumn{4}{|c|}{ Pengetahuan dan Perilaku Kesehatan Reproduksi Remaja } & \multirow{3}{*}{ Nilai $\mathrm{p}$} \\
\hline & \multicolumn{2}{|c|}{ Tinggi } & \multicolumn{2}{|c|}{ Rendah } & \\
\hline & $\mathrm{n}$ & $\%$ & $\mathrm{n}$ & $\%$ & \\
\hline \multicolumn{6}{|l|}{ Masa subur } \\
\hline Memadai & 6 & 1,2 & 48 & 9,7 & \multirow[t]{2}{*}{0,430} \\
\hline Tidak memadai & 35 & 7,1 & 407 & 82,1 & \\
\hline \multicolumn{6}{|l|}{ Hamil sekali hubungan } \\
\hline Memadai & 44 & 8,9 & 10 & 2,0 & \multirow[t]{2}{*}{0,082} \\
\hline Tidak memadai & 305 & 61,5 & 137 & 27,6 & \\
\hline \multicolumn{6}{|c|}{ Umur perempuan sebaiknya menikah pertama } \\
\hline Memadai & 4 & 0,8 & 50 & 10,1 & \multirow[t]{2}{*}{0,723} \\
\hline Tidak memadai & 44 & 8,9 & 398 & 80,2 & \\
\hline \multicolumn{6}{|c|}{ Umur laki-laki sebaiknya menikah pertama } \\
\hline Memadai & 12 & 2,4 & 42 & 8,5 & \multirow[t]{2}{*}{0,122} \\
\hline Tidak memadai & 149 & 30,0 & 293 & 59,1 & \\
\hline \multicolumn{6}{|l|}{ Rencana menikah } \\
\hline Memadai & 31 & 6,25 & 23 & 4,6 & \multirow[t]{2}{*}{0,430} \\
\hline Tidak memadai & 224 & 45,2 & 218 & 43,9 & \\
\hline \multicolumn{6}{|c|}{ Umur perempuan sebaiknya punya anak pertama } \\
\hline Memadai & 47 & 9,5 & 7 & 1,4 & \multirow[t]{2}{*}{1,000} \\
\hline Tidak memadai & 381 & 76,8 & 61 & 12,3 & \\
\hline \multicolumn{6}{|c|}{ Umur terendah aman melahirkan } \\
\hline Memadai & 8 & 1,6 & 46 & 9,3 & \multirow[t]{2}{*}{0,015} \\
\hline Tidak memadai & 24 & 4,8 & 418 & 84,3 & \\
\hline \multicolumn{6}{|c|}{ Umur tertinggi aman melahirkan } \\
\hline Memadai & 11 & 2,2 & 43 & 8,7 & \multirow[t]{2}{*}{1,000} \\
\hline Tidak memadai & 88 & 17,7 & 354 & 71,4 & \\
\hline \multicolumn{6}{|c|}{ Akibat menikah muda bagi kesehatan ibu } \\
\hline Memadai & 9 & 1,8 & 45 & 9,1 & \multirow[t]{2}{*}{0,182} \\
\hline Tidak memadai & 43 & 8,7 & 399 & 80,4 & \\
\hline \multicolumn{5}{|c|}{ Akibat menikah muda bagi kesehatan anak } & \multirow{3}{*}{0,022} \\
\hline Memadai & 5 & 1,0 & 49 & 9,9 & \\
\hline Tidak memadai & 11 & 2,2 & 431 & 86,9 & \\
\hline \multicolumn{6}{|c|}{ Akibat menikah muda bagi psikologi } \\
\hline Memadai & 21 & 4,2 & 33 & 6,7 & \multirow[t]{2}{*}{0,812} \\
\hline Tidak memadai & 160 & 32,3 & 282 & 56,9 & \\
\hline Akibat menikah muda pa & sosial el & & & & \\
\hline Memadai & 6 & 1,2 & 48 & 9,7 & 0,643 \\
\hline Tidak memadai & 64 & 12,9 & 378 & 76,2 & \\
\hline
\end{tabular}

\section{PEMBAHASAN}

Sumber informasi yang diperoleh berhubungan dengan pengetahuan yang dimiliki remaja tentang KRR ${ }^{8}$. Tingkat pengetahuan seorang remaja tentang kesehatan reproduksi dipengaruhi oleh banyaknya informasi dari media massa yang mereka 
miliki ${ }^{9}$. Media informasi juga memberikan pengaruh terhadap pengetahuan remaja terhadap kesehatan reproduksi ${ }^{10}$. Sumber informasi yang diperoleh dari media, cenderung akan berpengaruh atau berhubungan dengan pengetahuan remaja tentang KRR. Sebaliknya, jika informasi yang diperoleh dari media tidak berhubungan dengan pengetahuan KRR, kemungkinan ada variabel lain yang justru lebih berpengaruh terhadap pengetahuan ketimbang informasi dari media. Tingginya kebutuhan informasi bagi masyarakat seiring dengan era globalisasi dan perkembangan daerah yang menjadikan kondisi masyarakat semakin maju 11.

Petugas kesehatan berperan besar dalam mengatasi persoalan pengetahuan KRR. Petugas kesehatan berperan dalam kehamilan remaja, di mana dengan peran dari petugas kesehatan dapat mengatasi masalah kehamilan pada remaja ${ }^{12}$. Sebaliknya penelitian yang dilakukan oleh Laili dkk (2019), mendapatkan tidak ada hubungan antara peran petugas kesehatan dengan praktik pemanfaatan pelayanan kesehatan peduli remaja, yang terkait dengan pengetahuan remaja tentang KRR ${ }^{13}$. Masyarakat juga berperan dalam membagi informasi tentang KRR kepada remaja ${ }^{14}$. Ini berarti masyarakat baik tokoh agama, tokoh masyarakat memiliki peran yang cukup signifikan dalam memberikan pengetahuan yang baik kepada remaja tentang KRR, karena remaja masih cenderung mendengar orang yang lebih tua daripada mereka, dan ini memberikan pengaruh positif dalam pengetahuan remaja tentang KRR. Kesehatan reproduksi adalah suatu keadaan sehat, secara menyeluruh mencakup fisik, mental dan kedudukan sosial yang berkaitan dengan alat, fungsi serta proses reproduksi, dan pemikiran kesehatan reproduksi 10 bukan hanya kondisi yang bebas dari penyakit, melainkan juga bagaimana seseorang dapat memiliki seksual yang aman dan memuaskan sebelum dan sudah menikah ${ }^{15}$.

Institusi pendidikan formal seperti sekolah memiliki peran besar terhadap pengetahuan yang diperoleh para remaja yang bersekolah, karena di sana sumber ilmu pengetahuan diberikan. Peran usaha kesehatan sekolah sangat baik dalam memberikan pengetahuan terhadap remaja mengenai KRR ${ }^{16}$. Pendidikan di sekolah juga khususnya intrakurikulum lebih mendukung pendidikan KRR ${ }^{17}$. Artinya pendidikan formal secara langsung sangat berperan penting dalam peningkatan pengetahuan remaja di sekolah. pendidikan formal juga memberikan dampak yang tidak kalah penting dengan pendidikan formal karena saling melengkapi. Demikian pula, pendidikan yang diperoleh langsung dari masyarakat melalui banyaknya kegiatan kemasyarakatan yang bisa memberikan edukasi kepada remaja terkait KRR. Pendidikan kesehatan reproduksi yang komprehensif memberikan kesempatan bagi remaja untuk megeksplorasi nilai-nilai dan sikap diri serta melatih kemampuan pengambilan keputusan, komunikasi dan keterampilan penekanan resiko di semua aspek seksualitas ${ }^{18}$.

\section{KESIMPULAN DAN SARAN}

Sumber informasi yang berasal dari media berhubungan secara signifikan dengan pengetahuan remaja tentang masa subur dan umur terendah aman melahirkan. Sumber informasi yang berasal dari petugas kesehatan/masyarakat berhubungan secara signifikan pengetahuan remaja tentang perempuan akan hamil hanya sekali melakukan hubungan seks, rencana menikah, umur terendah aman melahirkan. Variabel pengetahuan remaja tentang kesehatan reproduksi yang berhubungan signifikan dengan sumber informasi dari institusi yaitu umur terendah aman melahirkan, akibat menikah muda bagi kesehatan anak.

Sebagian besar remaja di Sulawesi Utara tidak mendapatkan informasi yang memadai dari berbagai pihak seperti petugas kesehatan/masyarakat, institusi dan juga dari media. Ini menunjukkan bahwa ada banyak persoalan dari berbagai pihak yang tidak menjalankan edukasi kepada remaja di Sulawesi Utara untuk memberikan pemahaman yang baik tentang kesehatan reproduksi, dan ini dapat berakibat pada penyimpangan seksual bagi remaja tersebut.

\section{DAFTAR PUSTAKA}

1. Pakasi DT, Kartikawati R. Antara Kebutuhan dan Tabu: Pendidikan Seksualitas dan Kesehatan Reproduksi bagi Remaja di SMA. Makara Seri Kesehatan. 2013;17(2):79-87.

2. Solehati T, Rahmat A, Kosasih CE. Relation of Media on Adolescents' Reproductive Health Attitude and Behaviour. Jurnal Penelitian Komunikasi dan Opini Publik. 
2019;23(1):40-53.

3. Uyun Z. Peran Orangtua Dalam Pendidikan Kesehatan Reproduksi. In: Prosiding Seminar Nasional Parenting. Surakarta: Universitas Muhammadiyah Surakarta; 2013. p. 356-72.

4. Kusworo T, Ritohardoyo S, Sutomo AH. Hubungan Antara Akses Informasi Kesehatan Reproduksi dengan Perilaku berisiko Napza pada Remaja di Indonesia. Majalah Geografi Indonesia. 2014;28(2):179-87.

5. Ikhsanudin M, Nurjanah S. Dampak Pernikahan Dini Terhadap Pendidikan Anak Dalam keluarga. Al I’tibar : Jurnal Pendidikan Islam. 2018;5(1):38-44.

6. Iswarati. Pengetahuan dan Sumber Informasi Kesehatan Reproduksi Remaja di Indonesia. MANAJERIA. 2011;9(18):1-16.

7. Samidah I, Murwati, Yuhasri E. Correlation between The Utilization of Healthy Reproduction Information Source with PreMarried Sex Attitude and Act On Adolescent at SMAN 1 KAUR in 2017. Journal of Nursing and Public Health. 2017;5(2):60-7.

8. Cahyani KOA, Agushybana F, Nugroho RD. Hubungan Pola Komunikasi Orang Tua Asuh dengan Pengetahuan dan Sikap Kesehatan Reproduksi Remaja Panti Asuhan Kabupaten Klaten Tahun 2020. Jurnal Kesehatan Reproduksi. 2021 Aug 30;12(1):15-25.

9. Hakim A, Kadarullah O. Pengaruh Informasi Media Massa Terhadap Pengetahuan Kesehatan Reproduksi Pada Siswa SMA. Psycho Idea. 2016 Feb 1;14(1):31-40.

10. Ariki RD, Ulandari D. Hubungan Media Informasi, Pengaruh Teman, Tempat Tinggal dengan Pengetahuan Kesehatan Reproduksi pada Remaja di Kota Palembang Tahun 2017. Jurnal Kedokteran dan Kesehatan. 2018 Oct 4;14(2):39-46.

11. Sjuchro DW, Hariyanto F, Yusup E, Abidin Z. Program Siaran Radio Pemerintah Sturada 104.00 FM dalam Memenuhi Kebutuhan akan Informasi Mahasiswa Ilmu Komunikasi Universitas Singaperbangsa Karawang. Jurnal Politikom Indonesiana. 2018 Jul 31;3(1):4141.

12. Ramadani M, Nursal DGA, Ramli L. Peran Tenaga Kesehatan dan Keluarga dalam Kehamilan Usia Remaja. Kesmas: Jurnal Kesehatan Masyarakat Nasional (National Public Health Journal). 2015 Nov 8;10(2):8792.

13. Laili AN, Riyanti E, Bm S. Faktor-Faktor yang Berhubungan dengan Praktik Pemanfaatan Pelayanan Kesehatan Peduli Remaja (PKPR) oleh Remaja di Wilayah Kerja Puskesmas Bandarharjo Kota Semarang. Jurnal Kesehatan Masyarakat (Undip). 2019 Jan 2;7(1):421-9.

14. Nurmansyah MI, Al-Aufa B, Amran Y. Peran
Keluarga, Masyarakat dan Media Sebagai Sumber Informasi Kesehatan Reproduksi Pada Mahasiswa. Jurnal Kesehatan Reproduksi. 2012;3(1 Apr):16-23.

15. Nugroho T. Buku Ajar Ginekologi. Yogyakarta: Nuha Medika; 2010.

16. Budiono MA, Sulistyowati M. Peran UKS (usaha kesehatan sekolah) dalam penyampaian informasi kesehatan reproduksi terhadap siswa SMP Negeri X di Surabaya. Jurnal Promkes. 2013;1(2):184-91.

17. Masfiah S, Shaluhiyah Z, Suryoputroa A. Pendidikan Kesehatan Reproduksi Remaja (PKRR) Dalam Kurikulum SMA Dan Pengetahuan \& Sikap Kesehatan Reproduksi Siswa. Jurnal Promosi Kesehatan Indonesia. 2016 Dec 1;8(1):69-78.

18. Miswanto M. Pentingnya Pendidikan Kesehatan Reproduksi dan Seksualitas pada Remaja. Jurnal Studi Pemuda. 2016 Jun 23;3(2):111-21. 